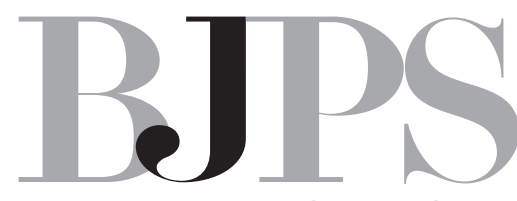

Brazilian Journal of

\title{
Pharmaceutical sciences scenario in CNPq research fellowship
}

Indicators of quality of research-related activities and graduate programs in the field of Pharmaceutical Sciences experienced a significant improvement over the past years. Today, the field has approximately 60 graduate programs in which 800 Faculty members serve as mentors, contributing to the personal and professional development of students seeking MS and PhD degrees. This growth has generated an increase in the demand for research fellowships.

A meeting to review 158 investigators with active (ongoing) fellowships took place in April 2013. Based on productivity, activity in Pharmaceutical Science area and evaluation by the members of the pharmacy review committee, the promotion of 42 awardees was recommended and prioritized according to their performance. The CNPq board of directors accepted sixteen of these recommendations, and the ranking of these investigators was altered to a higher level.

A meeting to review 120 regular applications and one application to a senior research fellowship was conducted in October 2013. No new fellowship was conceded by CNPq; only 46 awards (which are actually expiring fellowships) were available. It is worth noting that, according to CNPq policy, fellowship renewal is not allowed and all applicants can compete equally for the award. Application review was conducted according to the pre-established criteria available at the CNPq homepage. The committee made 105 recommendations $(86.8 \%)$. Among them, the committee recommended high priority funding of 47 (38.3\%) applicants at various levels according to their performance during the period considered, and funding with subsequent priority of 58 applications. The remaining 16 (13.2\%) applicants were not recommended for funding.

These results demonstrate the existence of qualified applicants (86.8\%), but also the shortage of fellowships (39\% of the demand, considering fellowships expiring in February 2014). This has occurred repeatedly over the past years. The insufficient number of awards has generated multiple manifestations from the members of the review committee to the CNPq Director. In spite of the funding level rise in previous years, the shortage still exists. This situation increases competition among applicants and sets the standard bar higher, which may cause some discouragement. Overall, the improvement in the quality of projects and scientific publications has been evident, which is important for the scientific and technological development of the pharmaceutical sciences field, and highlights the need to intensify research-related activities if one is interested in obtaining 


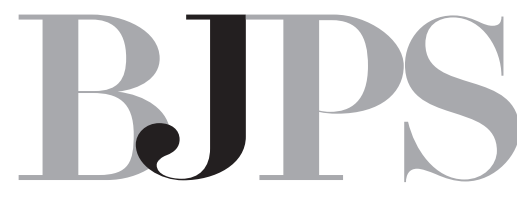

Brazilian Journal of Pharmaceutical Sciences

BRAZILIAN JOURNAL OF

PHARMACEUTICAL SCIENCES

and maintaining a fellowship. We would also like to mention the decease of two qualified awardees, and the subsequent request of these committee members to maintain the funds available for the area.

Additionally, we would like to remind all Colleagues that are reaching retirement age but wish to remain active and productive, the possibility to apply for a Senior Research fellowship.

\author{
Silvia Stanisçuaski Guterres \\ João Luis Callegari Lopes \\ Eliezer J. Barreiro \\ João Carlos Palazzo de Mello \\ Members of CA-FR at CNPq
}

